\title{
Individual differences in the way observers perceive humour styles
}

\author{
Robyn Brown \\ Swinburne University of Technology \\ robynbrown@swin.edu.au
}

\section{Bruce Findlay}

Swinburne University of Technology

bfindlay@swin.edu.au

\section{Jay K Brinker}

University of Alberta

jbrinker@ualberta.ca

\begin{abstract}
Humour has been conceptualised as styles, which vary based on their function (Martin et al. 2003). Research examining if and how observers perceive this intent is limited. The current study addresses this research gap by examining the perceptions of Martin et al.'s (2003) four humour styles. Additionally and of particular interest was whether self-defeating humour and another self-disparaging humour style, namely self-deprecating humour, were perceived as two independent humour styles. Despite being similar in content, self-deprecating humour is associated with higher self-esteem and self-defeating humour with lower self-esteem. Two hundred and four students watched comedy clips and completed a survey online. Participants were asked to categorise each video clip by humour style and to rate the self-esteem of the target (i.e. producer). Results revealed that humour styles are distinguishable by observers with participants' predominantly selecting one humour style over the others for each clip. In support of the second hypothesis, targets who were categorised as using self-deprecating humour were perceived as having higher self-esteem than those categorised as using self-defeating humour, illustrating a distinction in the perception of these humour styles at an interpersonal level.
\end{abstract}

Keywords: humour, self-defeating humour, self-deprecating humour, self-esteem, perception. 


\section{Introducing humour}

Humour is conceptualised as an interpersonal phenomenon that influences social interactions (Martin 2007). Having a sense of humour is important in establishing and maintaining social networks and is a means of signalling one's position within a social group (Zeigler-Hill et al. 2013). While humour is often touted as universally adaptive, Martin et al. (2003) proposed that humour consists of both adaptive and maladaptive styles. Research has investigated humour as intrapersonal, focusing on the person's use of humour and their own characteristics (e.g., self-esteem, personality; Galloway 2010; Saroglou \& Scariot 2002; Martin et al. 2003; Vernon et al. 2008; Veselka et al. 2010). Given that humour largely occurs within a social context, it is surprising there is only limited research examining humour interpersonally. There is research examining the appreciation of humour, however there is very little research investigating observers' perceptions of humour styles (Ruch 1998; Martin 2006; Cann \& Matson 2014).

\subsection{Multidimensional model of humour: Humour styles}

The most popular contemporary model of humour views humour as styles based on their function, either adaptive or maladaptive (Martin et al. 2003). The first of the two adaptive styles is affiliative humour, which serves to enhance interpersonal cohesiveness and reduce tensions through the use of funny expressions, joke telling, and impulsive witty banter to amuse others. The second adaptive humour style is selfenhancing humour, which is the tendency to hold a humorous outlook on life even when one is unaccompanied, including regular amusement by the incongruities of life, remaining optimistic despite stress or adversity. Aggressive humour, the first maladaptive humour style, is defined as a means of enhancing oneself at the expense of relationships with others, ridiculing, or manipulating others in the form of sarcasm, teasing, mockery, vilification, and the use of offensive (e.g., racist) forms of humour. The second maladaptive humour style, self-defeating humour, is viewed as an attempt to gain the attention and approval of others at one's own expense. It is the over-use of self-disparaging humour to amuse others to ingratiate oneself as well as laughing along with others when being mocked or denigrated. It may be used as a form of defensive denial to hide one's inherent negative feelings or avoid dealing adaptively with personal or interpersonal difficulties (Martin et al. 2003; McCosker \& Moran 2012).

Another perspective of self-disparaging humour has been proposed, called selfdeprecating humour (Rawlings \& Findlay 2013). This form of humour involves making light of one's mistakes and faults in a self-accepting manner while not taking oneself too seriously. Rawlings \& Findlay (2013) examined whether this form of joking about oneself and one's limitations is conceptually distinct from Martin's selfdefeating humour. In examining the construct of self-deprecating humour, they revealed that self-deprecating humour was positively associated with self-esteem, extraversion, and psychological wellbeing (Rawlings \& Findlay 2013) and was therefore determined to be independent of self-defeating humour, which is negatively related to these individual variables (Martin et al. 2003). 


\subsection{Relationship between humour styles and intrapersonal variables}

Martin et al. (2003) suggested that individuals use humour in ways that reflect their wider personality traits and mental health and there is an sizable body of research demonstrating a fairly consistent pattern of relationships between the four humour styles, personality traits, and wellbeing variables (e.g., Galloway 2010; Martin et al. 2003; Saroglou \& Scariot 2002; Vernon et al. 2008; Veselka et al. 2010). Selfreported use of affiliative humour correlated positively with extraversion and openness to experience (Martin et al. 2003) and agreeableness (Saraglou \& Scariot 2002). Given that affiliative humour is used to build and maintain social networks, it might be viewed as a vehicle to achieve the social goals of those higher on extraversion. For example, it has also been established that those higher on extraversion are more socially adept (Funder 2000) and therefore are more likely to engage in adaptive humour styles that help in achieving pro-social goals. Much like extraversion, affiliative humour is positively correlated with self-esteem, positive affect, optimism and social support (Martin et al. 2003; Kazarian \& Martin 2006; Dozois et al. 2009).

Self-enhancing humour is positively correlated with extraversion, agreeableness and openness to experience, and is negatively correlated with neuroticism (Schermer \& Mackie 2008). Openness to experience is associated with having a good imagination and being more attentive to one's inner feelings, allowing one to be more able to laugh at the eccentricities of life - a key function of self-enhancing humour (Martin et al. 2003). This form of humour involves the ability to laugh at one's circumstances and as such is useful in coping with stress. The use of humour as a coping mechanism might reduce the experience of depression and negative affect explaining the negative relationship between self-enhancing humour and these variables (Frewen et al. 2008). In addition, people scoring higher on neuroticism are more likely to worry excessively and might not engage in useful coping tools such self-enhancing humour explaining the negative relationship between this humour style and neuroticism (Martin et al. 2003; Kazarian \& Martin 2006; Dozois et al. 2009).

The self-reported use of aggressive humour is positively associated with measures of neuroticism, hostility, aggression, and negatively correlated with agreeableness, conscientiousness, and relationship satisfaction (Martin et al. 2003; Dozois et al. 2009; Galloway 2010). Individuals who score lower on agreeableness are considered less co-operative and are less concerned with maintaining social harmony (Costa \& McCrae 1992), reducing their hesitancy to use humour that would hurt or demean others (Martin et al. 2003). Aggressive humour has also shown to be positively correlated with neuroticism, indicating that those who use aggressive humour are also likely to be lower on emotional stability.

Self-defeating humour is positively related to neuroticism and negatively correlated with conscientiousness (Saroglou \& Scariot 2002; Martin et al. 2003; Vernon et al. 2008; Veselka et al. 2010). It is possible that people who experience emotional instability, and greater negative emotions, might have more negative perceptions of oneself and see demeaning themselves as fitting (Mendiburo-Seguel et al. 2015). Conversely, those who make fun of themselves and accept others making fun of them could experience more negative emotions in response to that. The facets associated with low scores on conscientiousness, such as higher levels of impulsiveness and lower levels of forethought may contribute to the use of selfdefeating humour in social situations. Greater self-reported use of self-defeating humour is positively related to measures of psychological distress and dysfunction, 
including depression, anxiety, hostility, and psychiatric symptoms, and negatively related to self-esteem, psychological well-being, social support, and relationship satisfaction (Frewen et al. 2008; McCosker \& Moran 2012).

Rawlings \& Findlay (2013) predicted that self-defeating humour would differ from self-deprecating humour based on their hypothesised conceptual differences. Because self-defeating humour is associated negatively with self-esteem and wellbeing, it was hypothesised that individuals using this humour style believe the jokes they make about themselves and more importantly take the jabs and barbs to heart. Conversely, those using self-deprecating humour might not believe what they are saying about themselves and, even if there is truth behind the joke, the person is not hurt by the knowledge of their flaws. As such, it was predicted that self-deprecating humour would correlate positively with self-esteem and psychological wellbeing. A factor analysis showed that the items measuring self-deprecating humour were independent of Martin et al.'s (2003) four humour styles (Rawlings \& Findlay 2013). Predictions were supported and self-deprecating humour was positively associated with extraversion, higher levels of self-esteem, higher emotional self-efficacy, and greater psychological wellbeing. It is possible that those who utilise self-deprecating humour are more comfortable with their faults and are able to make light of them. Rawlings \& Findlay's (2013) research suggests that despite these jokes having the same content (i.e. a target making a joke about themselves), the targets differ on an intrapersonal level with those using self-deprecating humour being more extraverted and psychologically healthy than those using self-defeating humour.

\subsection{An interpersonal approach to humour styles}

Zeigler-Hill et al. (2013) argued that humour styles operate as a signal, communicating information about the target to their social environment. They conducted two studies to explore this. The first study recruited a number of participants (i.e. targets) who completed measures of their self-esteem, humour styles, and personality features. The researchers then recruited friends and family members of the targets and asked them to rate the target's humour style, their perceived selfesteem level, and perceived personality features. They found that the observers' ratings matched the target's ratings of their own humour styles. They also found both perceived and self-report humour styles were associated with the perceptions of the targets on other dimensions (e.g., self-report self-defeating humour was negatively correlated with perceived self-esteem). Their second study made use of written descriptions of a target to examine the romantic desirability of these targets based on their humour style. They revealed that those who were perceived as using benign humour styles (e.g., affiliative humour) were perceived as possessing attractive qualities (e.g., warmth-trustworthiness) and as such were viewed as being more desirable romantic partners. Consistent with these findings, Cann \& Matson (2014) found that observing humour helps in making social evaluations where the person using a particular humour style may be expected to possess other characteristics commonly associated with that humour style. For example, people seen to be using affiliative humour may be perceived to be more sociable.

\subsubsection{Perceiving self-disparaging humour}

Of particular interest for the current project is whether self-defeating and selfdeprecating humour styles would be perceived as being different given that they 
would manifest in the same way (i.e. a target making a joke about themselves). Is it possible for an observer to discern if a target is using self-defeating humour or selfdeprecating humour? If they are able to differentiate, is this related to their perception of the target's self-esteem. Ziegler-Hill et al. (2013) examined the perception of selfesteem, asking perceivers to rate a known target's self-esteem and they found observer ratings were reasonably close to the target's rating of themselves. Given the different relationship between self-esteem and the two self-disparaging humour styles, the current study will investigate if an observer can differentiate between selfdeprecating and self-defeating humour and if their categorisation is related to their perception of the target's self-esteem. Taking this into account, we hypothesised that participants would differentially categorise humour videos into self-deprecating and self-defeating and this categorisation would relate to their ratings of the target's selfesteem. In other words, those targets rated as having a higher self-esteem, would more likely be categorised as using self-deprecating humour and those rated as having a lower self-esteem would be categorised as using self-defeating humour.

\subsubsection{Intrapersonal variables as contributing factors in perception}

There is limited literature available on perceiving humour, but given humour's relationship to personality, an examination of the literature on the perception of personality may provide guidance for this research. Funder's (1995: 656) Realistic Accuracy Model (RAM) claims that accuracy in judging traits in others is dependent on the "availability, detection, and utilisation of relevant behavioural cues". The use of humour may act as a behavioural cue that others can detect and use to make judgements about the target's personality. As shown in Ziegler-Hill et al.'s (2013) and Cann \& Matson's (2014) research, humour styles did signal a target's personality traits and self-esteem. Whilst RAM focuses on the accuracy of one's judgement of another's traits, assumed similarity, the extent to which an observer applies their perception of themselves to the target, might explain the process of humour perception more clearly. This self-based heuristic posits that observer's project their own characteristics onto others, especially in the absence of information, to assess a target (Ready et al. 2000). Research has found evidence of assumed similarity in the ratings of many traits and supports the suggestion that assumed similarity is a strategy to make judgments when we do not have sufficient information about a target's personality (Watson et al. 2000). If individuals use information about their own personality when asked to judge the personality of others, it is possible that when asked to rate the humour use in others, people would again project information about their own humour use.

Therefore, it is possible that an individual's characteristics are not only related to their own use of humour, but also their perception of humour as an observer. There are a number of explanations to illustrate this. Individuals who are higher on extraversion might be more likely to utilise adaptive humour styles, and therefore more likely to perceive this style. Another explanation might be that individuals higher on extraversion have higher self-esteem, and therefore are less offended by aggressive humour and ultimately less likely to see it as aggressive. Similarly, those who have higher levels of neuroticism may be more likely to use maladaptive humour styles, particularly self-defeating humour (Martin et al. 2003) and hence might perceive any self-disparaging joke as being self-defeating. The opposite might occur with individuals who have a higher self-esteem, who may perceive self-disparaging humour as self-deprecating. Despite our growing understanding of the use of different 
humour styles, little is known about the perception of it or what observer variables are related to that perception.

\subsection{Research questions and aims}

Humour forms part of our social repertoire and as such understanding it as a communication tool (Lunch 2002) is essential. This study adds to the body of research examining humour as an interpersonal signal (Ziegler-Hill et al. 2013) with the inclusion of self-deprecating humour. The authors also aimed to examine whether self-deprecating humour would be perceived as a distinct style when compared with self-defeating humour given that they would present in the same way. Therefore, this study provides a unique opportunity to examine subtle nuances in humour use. The current study examined whether observers are able to perceive the different humour styles, including self-deprecating humour. In particular, whether observers are able to discern the subtle differences between self-defeating and self-deprecating humour, presenting a unique opportunity to explore the perception of humour styles. This paper also investigated whether observer characteristics (e.g., self-esteem, wellbeing, humour styles, mood, and personality) related to their perception of the humour styles. For example, are positive traits (i.e. observer positive affect, extraversion, and higher self-esteem and wellbeing) positively related to the perception of self-deprecating humour?

\section{Method}

\subsection{Participants}

Students from a third year psychology class were invited to participate as part of their course, and to share the survey with friends and family members. Of the 204 participants, just over 70\% were Australian born. There were $152(75 \%)$ women and $52(25 \%)$ men with a mean age range of $18-24$. For $72 \%$ of the participants, their highest level of education was a partially completed degree, $13 \%$ of the participants had completed a degree and $2 \%$ of the participants had a postgraduate degree, indicating that over $80 \%$ of the sample was university educated.

\subsection{Measures}

An online survey was used for data collection including demographics (age, sex, nationality, and first language) and a series of questionnaires. Due to the exploratory nature of this study, participants' self-esteem, humour styles, personality, mood, emotional intelligence, and wellbeing were measured and were included as potential predictors of humour perception in this study.

\subsubsection{Rosenberg's (1965) self-esteem scale}

The Rosenberg Self Esteem scale is a measure of self-worth and consists of 10 items. Participants rate their agreement with the items on a four-point scale with responses ranging from 1 (Strongly Disagree) to 4 (Strongly Agree). An example of an item is "On the whole I am satisfied with myself". Four items representing low self-esteem were reverse scored. Scores range from 10-40 with higher scores representing greater 
self-esteem. The scale has shown good internal consistency (Cronbach's $\alpha=.77$; Rosenberg 1965).

\subsubsection{The international personality item pool (IPIP-5-50; Goldberg 1992)}

The International Personality Item Pool-5-50 is a 50-item self-report personality questionnaire designed to measure the domain constructs of the Five Factor Model, as expressed in Costa and McCrae's (1992) revised NEO personality inventory (NEOPI-R). The five domains are Extraversion (e.g., "Am the life of the party"), Emotional Stability (reversed neuroticism; e.g., "Get stressed out easily"), Openness (e.g., "Have a rich vocabulary"), Agreeableness (e.g., "Make people feel at ease"), and Conscientiousness (e.g., "Am always prepared"). Participants indicate the degree to which each statement accurately describes them on a five-point Likert scale with anchors 0 (This statement definitely does not describe you) and 4 (This statement describes you very well). The average rating across items on each factor was calculated. All scales have been shown to have good to excellent internal consistency (Extraversion $\alpha=.88$, Agreeableness $\alpha=.79$, Conscientiousness $\alpha=.81$, Emotional Stability $\alpha=.82$, and Openness $\alpha=.82$; Donnellan et al. 2006).

\subsubsection{The positive and negative affect scale (PANAS; Watson et al. 1988)}

The PANAS was used to measure participants' levels of current affect. This scale is comprised of 60 words describing different feelings and emotions, which fall into two factors; Positive Affect (e.g., "attentive") and Negative Affect (e.g., "irritable"). Participants indicate the degree to which each word accurately describes their experience over the past day using a five-point Likert scale with anchors 0 (Very Slightly or Not at All) and 4 (Extremely). Both sub-scales showed good to excellent internal consistency (Positive Affect $\alpha=.90$ and Negative Affect $\alpha=.87$; Watson et al. 1988).

\subsubsection{Attitudes to life scale (Ryff 1989)}

The Attitudes to Life questionnaire was used to measure participants' psychological wellbeing. This scale measures multiple facets of wellbeing including self-acceptance, positive relations with others, autonomy, environment mastery, purpose in life and personal growth, although the current study used the total score as a measure of general wellbeing. This version of the scale consists of 18 items and is measured on a 6-point Likert scale with anchors of 1 (Strongly Disagree) and 6 (Strongly Agree). The relevant items were reverse-coded, and final scores for wellbeing were computed by summing all of the items. Whilst Ryff \& Keyes (1995) suggested that the 18-item version is comparable to the original 120 -item scale, the sub-scales have low to moderate internal consistency $(\alpha=.26-\alpha=.52$; Clarke et al. 2001). However, the current study examined wellbeing as a whole and as such the 18 -item scale was sufficient revealing excellent internal consistency within the current study $(\alpha=.86)$.

\subsubsection{Humour styles questionnaire (Martin et al. 2003)}

This scale was used to measure the way in which participants use humour themselves (Martin et al. 2003). The scale contains 32 items and produces four sub-scales: Affiliative ("I laugh and joke a lot with my closest friends"), Self-Enhancing (e.g., 
"Even when I'm by myself, I'm often amused by the absurdities of life"), SelfDefeating (e.g., "I often go overboard in putting myself down when I am making jokes or trying to be funny"), and Aggressive (e.g., "If I don't like someone, I often use humour or teasing to put them down") humour. Participant responses are on a 7point Likert scale, with 1 (Totally Disagree) and 7 (Totally Agree). The subscale scores are computed by summing the relevant items producing possible scores from 8 to 56, with higher scores indicating greater use of that humour style. Each sub-scale showed good reliability (Affiliative $\alpha=.80$, Self-Enhancing $\alpha=.81$, Aggressive $\alpha=.77$, and Self-Defeating $\alpha=.80$; Martin et al. 2003).

\subsubsection{Self-deprecating scale (Rawlings \& Findlay 2013)}

This scale was used to measure participants' use of self-deprecating humour and consists of 13-items divided into two sub-factors: Personal Self-Deprecating Humour (e.g, "Laughing at myself helps me not to take myself too seriously") and Social SelfDeprecating Humour (e.g., "People like me when I tell humorous stories about myself"). Participants recorded their responses on a 5-point Likert scale, with 1 (Strongly Disagree) to 5 (Strongly Agree). The subscales have been shown to have excellent internal reliability (Personal $\alpha=.87$ and Social $\alpha=85$; Brown \& Findlay 2013).

\subsubsection{The emotional self-efficacy scale (Kirk et al. 2008)}

This scale was used to measure participants' confidence to act in an emotionally intelligent way. This scale consists of 32 items, with eight items for each of the four branches (sub-scales) of Emotional Intelligence proposed by Mayer et al. (2004). These are (a) Understand (e.g., "Understand what causes your emotions to change"), (b) Perceive (e.g., "Correctly identify your own positive emotions"), (c) Regulate (e.g., "Change your negative emotion to a positive emotion"), and (d) Facilitate emotions (e.g., "Get into a mood that best suits the occasion"). Participants are required to rate their confidence in their ability to enact each item on a five point Likert scale, from 1 (Not at all confident) and 5 (Very confident). For the purpose of the current study, two scores were computed. A total emotional self-efficacy score was computed by summing all of the items, with higher scores indicating higher levels of emotional self-efficacy. A second emotion perception score was also computed by summing all of the "perceive branch" items, with higher scores indicating higher levels of emotion perception. Kirk et al. (2008) revealed that the measure of emotional self-efficacy showed excellent internal consistency $(\alpha=0.96)$. The sub-scale, "Perceive Emotional Self-Efficacy" revealed good internal consistency $(\alpha=.80)$ in Dacre Pool \& Qualter's (2012) study.

\subsection{Materials}

\subsubsection{Humour style video clips}

Fifteen short video clips of internationally known stand-up comedians obtained from an online video publisher (YouTube) were used to illustrate the five humour styles. These videos were chosen based on the theoretical definitions of the humour styles, and the three authors agreed on the selection of these videos as representing each humour style. For example, a video was chosen as an example of aggressive humour 
if it showed ridiculing others (i.e. individuals or groups), in the form of sarcasm, teasing, mockery, or vilification. Videos showing a comedian telling benign jokes with the apparent aim of amusing the audience were selected as demonstrating affiliative humour. Because it was not yet possible to empirically discern selfdeprecating from self-defeating humour, several videos were included where participants made jokes about themselves and were examined as possible illustrations for both.

\subsubsection{Post-humour stimuli questions}

After viewing each video, participants were asked to rate how funny they found the video on a scale of 1 ("Not at all") to 5 ("Extremely"), and their perception of the comedian's self-esteem on a scale of 1 ("Very Low") and 5 ("Very High"). Finally, the participants were provided with definitions of each of the humour styles and asked to select which style they thought the comedian was utilising. The target's self-esteem, funniness, and humour style were the dependent variables of this study.

\subsection{Procedure}

Participants were provided with a link to the anonymous online survey via the course website. The first screen of the survey provided participants with information about the study and their rights as participants. Completion of the survey was taken as consent to participate. The survey began with demographic questions followed by the questionnaires and finally the videos and corresponding questions.

\subsection{Statistical analyses}

\subsubsection{Data screening}

The data were screened for out of range values, missing values and univariate outliers. There were no out of range values present in the dataset; however, there were a few missing values for individual questionnaire items. There was no pattern of missing values, with no missing values across cases on the same item. Prior to computing scores for each scale, all of the missing values were replaced with the mean of the remaining items in the scale for that case. The few univariate outliers for each of the variables were replaced with a value three standard deviations from the mean thus reducing these scores to normal (Tabachnik \& Fidell 2001).

\subsubsection{Video exemplars}

One video for each humour style was selected as an exemplar for analyses. The video with the highest degree of variation in categorisation was chosen to increase the variability that could be accounted for by observer characteristics. It is important to note that self-enhancing humour was not the most prominent humour style for any of the fifteen videos and hence there is no exemplar video for this humour style.

\section{Results}

The means, standard deviations, reliability scores, and intercorrelations are displayed in Table 1 below. 
Table 1. Means, Standard Deviations, Cronbach's Alphas, and Inter-Correlations for all of the Variables Examined in the Study.

\section{Humour styles}

Affiliative Aggressive Self-enhancing Self-defeating Personal SDHum Social SDHum $\quad M \quad S D$ Cronbach's $\alpha$

\begin{tabular}{|c|c|c|c|c|c|c|c|c|c|}
\hline \multicolumn{10}{|l|}{ Wellbeing variables } \\
\hline Wellbeing & $.37^{* *}$ & $-.31 * *$ & $.30^{* *}$ & $-.42 * *$ & $.26 * *$ & $-.25 * *$ & 68.63 & 8.81 & .86 \\
\hline Self-esteem & $.27 * *$ & $-.22 * *$ & $.45^{* *}$ & $-.52 * *$ & $.15^{*}$ & $-.37 * *$ & 29.58 & 5.04 & .90 \\
\hline Positive affect & $.24 * *$ & $-.18 * *$ & $.45^{* *}$ & $-.29 * *$ & $.16^{*}$ & $-.25 * *$ & 30.45 & 8.35 & .91 \\
\hline Negative affect & $-.29 * *$ & $.28 * *$ & $-.27 * *$ & $.41 * *$ & $-.23 * *$ & $.14^{*}$ & 19.3 & 7.22 & .89 \\
\hline Emotional self-efficacy & $.31^{* *}$ & -01 & $.37 * *$ & $-.19 * *$ & $.24 * *$ & -.02 & 120.88 & 14.00 & .94 \\
\hline Perceive ESE & $.32 * *$ & $-.19 * *$ & $.28^{* *}$ & $-.16^{*}$ & $.33 * *$ & -.03 & 28.01 & 3.31 & .82 \\
\hline \multicolumn{10}{|l|}{ Personality variables } \\
\hline Extraversion & $.45 * *$ & .05 & $.27 * *$ & -.13 & $.21 * *$ & -.09 & 31.75 & 8.47 & .91 \\
\hline Emotional stability & $.26^{* *}$ & $-.21 * *$ & $.48^{* *}$ & $-.42 * *$ & $.19 * *$ & $-.20 * *$ & 29.98 & 8.04 & .88 \\
\hline Openness & $.27 * *$ & $-.13 * *$ & $.30 * *$ & $-.17 *$ & .13 & $-.15 * *$ & 37.37 & 4.88 & .79 \\
\hline Agreeableness & $.26^{* *}$ & $-.41 * *$ & $.22 * *$ & $-.18 * *$ & $.22 * *$ & $-.17 * *$ & 41.1 & 5.15 & .84 \\
\hline Conscientiousness & .05 & $-.33 * *$ & .13 & -0.32 & 0.03 & $-.30 * *$ & 34.43 & 6.78 & .81 \\
\hline \multicolumn{10}{|l|}{ Humour styles } \\
\hline Affiliative humour & - & -.01 & $.37 * *$ & -.06 & $.43 * *$ & .11 & 46.53 & 6.50 & .86 \\
\hline Aggressive humour & & - & -.09 & $.31 * *$ & .01 & .11 & 26.8 & 7.91 & .87 \\
\hline Self-enhancing humour & & & - & -.12 & $.39 * *$ & .08 & 36.05 & 9.39 & .84 \\
\hline Self-defeating humour & & & & - & $.20 * *$ & $.61 * *$ & 28.76 & 10.02 & .84 \\
\hline Personal SDHum & & & & & - & $.41 * *$ & 25.98 & 3.95 & .84 \\
\hline Social SDHum & & & & & & - & 18.32 & 4.88 & .84 \\
\hline
\end{tabular}

$*=p<.001 ; *=p<.05$. SDHum $=$ Self-Deprecating Humour, $\mathrm{SD}=$ Standard Deviation, ESE $=$ Emotional Self-Efficacy 


\subsection{Perception of humour styles}

To test the first hypothesis, a frequencies analysis was conducted to analyse which humour styles were most frequently selected to represent each video clip. The percentages for each video clip are shown in Table 2 .

Table 2. Frequencies of selected humour styles for each video.

\begin{tabular}{clll}
\hline Video & $\begin{array}{c}\text { Humour style by theoretical } \\
\text { definition }\end{array}$ & Most common categorisation & $\begin{array}{c}\text { Number of } \\
\text { participants (\%) }\end{array}$ \\
\hline 1 & Affiliative humour & Affiliative humour & $127(62.3)$ \\
2 & Self-enhancing humour & Self-deprecating humour & $138(67.7)$ \\
3 & Aggressive humour & Aggressive humour & $139(68.1)$ \\
4 & Self-disparaging humour & Self-defeating humour & $94(46.1)$ \\
5 & Affiliative humour & Affiliative humour & $116(56.9)$ \\
6 & Aggressive humour & Affiliative humour & $68(33.3)$ \\
7 & Self-disparaging humour & Self-defeating humour & $108(52.9)$ \\
8 & Affiliative humour & Affiliative humour & $126(61.8)$ \\
9 & Affiliative humour & Affiliative humour & $92(45.1)$ \\
10 & Self-disparaging humour & Self-defeating humour & $102(50.0)$ \\
11 & Self-disparaging humour & Self-deprecating humour & $102(50.0)$ \\
12 & Aggressive humour & Affiliative humour & $125(61.3)$ \\
13 & Self-disparaging humour & Self-defeating humour & $112(54.9)$ \\
14 & Self-enhancing humour & Self-deprecating humour & $99(48.5)$ \\
15 & Self-enhancing humour & Self-deprecating humour & $81(31.7)$ \\
\hline
\end{tabular}

Self-enhancing humour was not chosen as the predominant category for any of the videos. This is likely due to the internal nature of self-enhancing humour where its expression would inevitably be perceived as one of the remaining humour styles. In the current study it was most often interpreted as self-deprecating. Another interesting finding was that for the videos that were selected as displaying theoretical aggressive humour, two out of three of these videos were perceived as affiliative.

\subsection{Individual differences and humour style perception}

The results of the Multinomial Logistic Regressions, which analysed the observer characteristics that predicted the categorisation of humour, are displayed in Table 3 below. 
For the affiliative humour video, the overall model was significant $\left(\chi^{2}(60)=82.94\right.$, $p=.03$ ), but only a few of the observer variables independently predicted which category the participants chose. Participants who reported lower wellbeing were less likely to select affiliative humour over aggressive humour and self-enhancing humour. Participants with higher levels of perceived emotional self-efficacy were more likely to rate the video as aggressive over affiliative. Participants with higher levels of negative affect and emotional stability were less likely to rate the video as affiliative rather than self-enhancing. Finally, participants who report using less affiliative humour and those who rate higher on extraversion were more likely to categorise this clip as affiliative over self-defeating.

For the aggressive humour video, the overall model was significant $\left(\chi^{2}(60)=88.84\right.$, $p=.01)$ but again, only some of the observer variables were independently related to which category they chose. Participants with lower levels of openness were more likely to categorise the video as affiliative over aggressive and those with higher selfreported negative affect were more likely to categorise the video as self-enhancing and self-defeating over aggressive humour.

For the self-defeating video, the overall model was significant $\left(\chi^{2}(60)=92.75\right.$, $p=.004)$, but few observer variables were significantly related to categorisation. Participants with lower levels of self-report perceive emotional self-efficacy were less likely to select affiliative humour over self-defeating and those with higher levels of self-reported emotional stability were more likely to select self-enhancing over selfdefeating humour.

Finally, for what the participants most often interpreted as the self-deprecating video, the overall model was significant $\left(\chi^{2}(60)=79.37, p=.05\right)$ with some of the observer variables significantly predicting categorisation. Participants with higher self-reported positive affect were more likely to categorise the video as affiliative over self-deprecating. Higher self-reported use of affiliative humour use was related to the selection of self-deprecating humour over self-enhancing humour and selfdefeating humour. Participants with higher levels of self-reported agreeableness were less likely to select self-deprecating over self-enhancing and self-defeating humour. 
Table 3. Multinomial Logistic Regression examining the influence of intrapersonal variables on humour style selection.

\begin{tabular}{|c|c|c|c|c|c|c|c|c|c|}
\hline Ref. category & Other HS & Covariates & coeffb & s.e. & Wald & $\mathrm{p}$-value & $\exp (b)$ & lower & upper \\
\hline \multicolumn{10}{|l|}{ Affiliative } \\
\hline & Aggressive & Wellbeing & -0.15 & 0.06 & 6.85 & 0.01 & 0.86 & 0.77 & 0.96 \\
\hline & & Perceive ESE & 0.29 & 0.11 & 6.53 & 0.01 & 1.34 & 1.07 & 1.67 \\
\hline & Self-enhancing & Wellbeing & -0.13 & 0.06 & 4.98 & 0.03 & 0.88 & 0.78 & 0.98 \\
\hline & & Negative affect & 0.12 & 0.05 & 5.45 & 0.02 & 1.13 & 1.02 & 1.24 \\
\hline & & Emotional stability & 0.13 & 0.06 & 5.05 & 0.03 & 1.14 & 1.02 & 1.28 \\
\hline & Self-defeating & Affiliative humour & 0.15 & 0.07 & 4.40 & 0.04 & 1.16 & 1.01 & 1.32 \\
\hline & & Extraversion & -0.13 & 0.05 & 6.62 & 0.01 & 0.88 & 0.80 & 0.97 \\
\hline \multicolumn{10}{|l|}{ Aggressive } \\
\hline & Affiliative & Openness & -0.10 & 0.05 & 3.96 & 0.05 & 0.90 & 0.82 & 1.00 \\
\hline & Self-enhancing & Negative affect & 0.21 & 0.07 & 8.38 & 0.00 & 1.23 & 1.07 & 1.41 \\
\hline & Self-defeating & Negative affect & 0.15 & 0.06 & 5.67 & 0.02 & 1.16 & 1.03 & 1.31 \\
\hline \multicolumn{10}{|l|}{ Self-defeating } \\
\hline & Affiliative & Perceive ESE & -0.34 & 0.16 & 4.69 & 0.03 & 0.71 & 0.52 & 0.97 \\
\hline & Self-enhancing & Emotional stability & 0.11 & 0.05 & 3.99 & 0.05 & 1.11 & 1.00 & 1.23 \\
\hline \multicolumn{10}{|c|}{ Self-deprecating } \\
\hline & Affiliative & Positive affect & 0.19 & 0.08 & 5.64 & 0.02 & 1.20 & 1.03 & 1.40 \\
\hline & Self-enhancing & Affiliative humour & -0.11 & 0.06 & 3.92 & 0.05 & 0.89 & 0.80 & 1.00 \\
\hline & & Agreeableness & 0.22 & 0.08 & 6.86 & 0.01 & 1.24 & 1.06 & 1.46 \\
\hline & Self-defeating & Affiliative humour & -0.09 & 0.04 & 4.69 & 0.03 & 0.92 & 0.85 & 0.99 \\
\hline & & Agreeableness & 0.23 & 0.06 & 5.19 & 0.02 & 1.14 & 1.02 & 1.27 \\
\hline
\end{tabular}

$N=204$; ESE=Emotional self-efficacy; Ref. category=Reference category (the most frequently selected humour style for that particular video).

Note: Contact authors for the full set of results 


\subsection{Self-defeating versus self-deprecating: An interpersonal perspective}

Participants were asked to rate the funniness of each video and the comedian's selfesteem. Frequencies were conducted to analyse the shape of the distribution and the results revealed that responses were clustered around the centre. Therefore, overall average scores of funniness and self-esteem were computed for the videos most frequently identified as self-deprecating and self-defeating. This was achieved by summing the scores for three self-defeating videos and for three self-deprecating videos and dividing them by the number of videos (three).

\subsubsection{Perceived self-esteem}

To examine whether there was a difference in the observer's perception of the comedians' self-esteem if the comedians were using humour most often identified as self-deprecating or self-defeating, a paired-sample t-test using the aforementioned average scores for each self-disparaging humour style was conducted. It revealed a significant difference $(t(203)=10.26, p<.001)$, where the average perceived selfesteem was significantly higher in the self-deprecating videos $(M=4.80, S D=.85)$ in comparison to the self-defeating videos $(M=4.15, S D=1.10)$.

Three linear regressions were conducted to assess if any observer variables were significant predictors of perceived self-esteem for the self-disparaging videos. The first linear regression examined wellbeing variables as predictors $(F$ self-deprecating $(6$, $203)=1.32, p=.25 ; F$ self-defeating $(6,203)=2.20, p=.04)$, the second regression examined observer humour styles as predictors, $\left(F_{\text {self-deprecating }}(5,203)=.39, p=.86 ; F_{\text {self-defeating }}(5\right.$, $203)=1.11, p=.36)$ ) and the third regression examined personality variables as predictors of self-disparaging videos $\left(F_{\text {self-deprecating }}(5,203)=.52, p=.76 ; F_{\text {self-defeating }}(5\right.$, $203)=1.21, p=.31$ ). These results of the regression can be seen in Table 4 below.

Observer positive affect was the only significant predictor of self-esteem ratings for the target using self-deprecating humour, with higher levels of observer positive affect predicting higher levels of perceived self-esteem of the self-deprecating comedians. Observer self-esteem was the only significant predictor of how participants rated the self-esteem of the comedians illustrating self-defeating humour. Higher self-reported self-esteem in the observer predicted higher perceived selfesteem of the comedian. 
Table 4. Regression statistics of predictors of target self-esteem using selfdisparaging humour.

\begin{tabular}{|c|c|c|c|c|c|}
\hline Observer variables & Variable & $\beta$ & & t-test & \\
\hline & & Self-deprecating & Self-defeating & Self-deprecating & Self-defeating \\
\hline \multicolumn{6}{|l|}{ Wellbeing } \\
\hline & Wellbeing & -0.04 & -0.2 & -0.34 & -1.92 \\
\hline & Self-esteem & -0.03 & 0.21 & -0.31 & $2.01 *$ \\
\hline & Negative affect & 0.09 & 0.04 & 1.01 & 0.49 \\
\hline & Positive affect & 0.17 & 0.14 & $1.96^{*}$ & 1.54 \\
\hline & ESE & 0.13 & 0.13 & 1.33 & 1.4 \\
\hline & Perceive ESE & -0.03 & -0.12 & -0.38 & -0.14 \\
\hline \multicolumn{6}{|l|}{ Humour styles } \\
\hline & Aggressive & -0.01 & 0.09 & -0.07 & 1.25 \\
\hline & Affiliative & 0.09 & -0.004 & 1.08 & -0.05 \\
\hline & Self-enhancing & 0.04 & 0.09 & 0.55 & 1.18 \\
\hline & Self-defeating & 0.01 & -0.13 & 0.12 & -1.64 \\
\hline & Self-deprecating & -0.04 & -0.01 & -0.46 & -0.1 \\
\hline \multicolumn{6}{|l|}{ Personality } \\
\hline & Extraversion & 0.05 & 0.05 & 0.71 & 0.6 \\
\hline & Agreeableness & 0.05 & 0.04 & 0.65 & 0.54 \\
\hline & Conscientiousness & 0.02 & -0.09 & 0.29 & -1.21 \\
\hline & $\begin{array}{l}\text { Emotional } \\
\text { Stability }\end{array}$ & 0.03 & 0.14 & 0.42 & 1.86 \\
\hline & Openness & -0.11 & -0.09 & -1.36 & -1.15 \\
\hline
\end{tabular}

$N=204, * \mathrm{p}=.05 ; \mathrm{ESE}=$ Emotional self-efficacy

\subsubsection{Perceived Funniness}

To examine whether there was a difference in participants' rating of funniness of the self-deprecating versus self-defeating videos, another paired-sample t-test using the aforementioned average scores for the self-disparaging humour styles was conducted. Participants rated the self-defeating videos to be more funny $(M=4.37, S D=1.25)$ than the self-deprecating videos $(M=4.12, S D=.96)$ and this difference was significant $(t$ $(203)=3.16, p=0.002)$.

Three linear regressions were conducted using the mean perceived funniness for the self-disparaging videos as the dependent variable and the results are displayed in Table 5 below. 
Table 5. Regression statistics of predictors of target self-esteem using selfdisparaging humour.

\begin{tabular}{llllll}
\hline \multirow{2}{*}{ Observer variables } & Variable & \multicolumn{2}{c}{$\beta$} & \multicolumn{2}{c}{ t-test } \\
& & Self-deprecating & Self-defeating & Self-deprecating & Self-defeating \\
\hline Wellbeing & & & & \\
& Wellbeing & 0.09 & 0.08 & 0.84 & 0.77 \\
& Self-esteem & -0.02 & -0.16 & -0.14 & -1.50 \\
& Negative affect & 0.16 & 0.17 & $1.95^{*}$ & $2.16^{*}$ \\
& Positive affect & 0.07 & 0.09 & 0.77 & 0.98 \\
& ESE & 0.14 & 0.21 & 1.49 & $2.28^{*}$ \\
& Perceive ESE & -0.06 & -0.18 & -0.64 & $-2.07^{*}$ \\
Humour styles & & & & \\
& Aggressive & 0.09 & 0.16 & 1.24 & $2.20^{*}$ \\
& Affiliative & 0.1 & 0.03 & 1.28 & 0.32 \\
& Self-enhancing & 0.07 & 0.05 & 0.90 & 0.61 \\
& Self-defeating & 0.06 & 0.16 & 0.73 & $2.13^{*}$ \\
& Self-deprecating & 0.08 & 0.05 & 0.93 & 0.59 \\
& & & & & \\
& Extraversion & 0.17 & 0.18 & $2.21^{* *}$ & $2.47^{*}$ \\
& Agreeableness & 0.02 & -0.1 & 0.24 & -1.27 \\
& Conscientiousness & -0.1 & -0.19 & -1.27 & $-2.66^{* *}$ \\
& Emotional stability & 0.08 & -0.06 & 1.07 & -0.87 \\
& Openness & -0.11 & 0.002 & -1.44 & 0.02 \\
\hline
\end{tabular}

$N=204 ; * \mathrm{p}<.05, \mathrm{p}<.01 ;$ ESE=Emotional self-efficacy

Similar to the self-esteem regression, the first regression examined wellbeing variables as predictors $\left(F_{\text {self-deprecating }}(6,203)=1.41, p=.21 ; F_{\text {self-defeating }}(6,203)=2.79\right.$, $p=.01)$ and the second regression examined humour styles as predictors $\left(F_{\text {self-deprecating }}\right.$ $(5,203)=2.14, p=.06 ; F$ self-defeating $(5,203)=3.23, p=.01)$ and the third regression examined personality variables $(F$ self-deprecating $(5,203)=1.87, p=10 ; F$ self-defeating $(5$, $203)=3.61, p=.004$ ) as predictors of the funniness for the self-disparaging videos. These results can be seen in Table 5 above.

Both self-reported extraversion and negative affect positively predicted of participants' ratings of funniness for the comedians illustrating both self-disparaging humour styles. Higher observer extraversion and negative affect predicted higher perceived funniness of the comedian. Observer self-reported use of aggressive humour and self-defeating humour along with emotional self-efficacy positively predicted the perception of funniness ratings of the self-defeating targets, whilst observer conscientiousness and the perceive branch of emotional self-efficacy negatively predicted funniness for the self-defeating videos. 


\section{Discussion}

Humour predominately occurs within a social context and examining it from an interpersonal perspective might provide a clearer understanding of the strategic uses of humour within discourse (Martin 2007; Cann \& Matson 2014). The current study investigated the perception of five humour styles and the observer variables that might relate to that perception. Most humour research has provided insight into the individual characteristics associated with humour production (i.e. the humour styles), and this study aimed to examine how these observer characteristics are involved with the perception of humour styles.

The hypothesis that participants would differentially categorise the videos into humour styles was supported in that there was relatively consistent agreement in categorising humour styles. Humour is considered an important form of communication (Lynch 2002) and this finding provides compelling evidence that Martin et al.'s (2003) humour styles are apparent on an interpersonal level. The accuracy in categorising the affiliative targets might indicate that affiliative may be more accurately perceived than self-enhancing and aggressive humour. The majority of the video clips selected as representing aggressive humour, were categorised as affiliative humour, which may suggest a few explanations. These findings might be explained by the context of the humour, which is likely to play a role in whether it is perceived as positive or negative. The video clips were of stand-up comedians teasing or ridiculing celebrities (e.g., Joan Rivers ridiculing Katie Holmes and Tom Cruise, Jack Whitehall mocking Robert Pattinson) or society as a whole (e.g., Stephen K Amos teasing Australia) and as a result may not have been construed as malicious. The delivery of stand-up comedy is likely to have removed the personal nature of the jokes, which may have been considered to be in good fun. Self-enhancing humour was not selected as the most common humour style for any of the videos presented, but this is likely due to the nature of self-enhancing humour which is used to benefit the individual rather than operate as a social tool (Martin et al. 2003). Interestingly, the majority of participants rated self-enhancing humour as self-deprecating. Given that the content of these video clips were optimistic in nature and revealed aspects of the comedian's internal dialogue (e.g., Ellen DeGeneres' thoughts on procrastination), it might provide further evidence that self-deprecating humour is perceived as positive.

Whilst there was agreement for humour style selection, the agreement was not unanimous and the individual difference variables of the observers may provide some explanation. The results showed no consistency in observer variables relating to how participants categorised the different videos into humour styles, but some interesting trends did appear. Observers who reported using more affiliative humour themselves were more likely to categorise a video as self-deprecating over self-defeating. Past research has proposed that self-deprecating humour may be a sub-type of affiliative humour (Martin et al. 2003) and the current finding supports the assumed similarity research which would suggest that those who engage in positive humour styles are more likely to assume that others also engage in positive humour in the absence of any other information. In addition, higher levels of extraversion were associated with the selection of affiliative humour over self-defeating humour. Individuals who engage in affiliative humour tend to be higher on extraversion as both constructs are driven by a strong desire for good social relationships (Martin et al. 2003), so it is possible that observers higher on self-report extraversion are more likely to engage in affiliative humour and when exposed to humour that was pro-social were more likely to accurately recognise it and categorise the video as being such. 


\subsection{Focusing on the self-disparaging styles}

To examine the way in which the self-defeating and self-deprecating humour styles were perceived, the observer ratings of self-esteem of the targets illustrating each style was analysed. Rawlings \& Findlay (2013) established that a key difference between self-defeating and selfdeprecating humour was their correlation with self-esteem, with individuals using selfdeprecating humour reporting a higher sense of self-worth. The current study confirmed that these subtle self-esteem differences were discernible on an interpersonal level and supported the hypothesis that the target categorised as using self-deprecating humour would be rated as having a higher self-esteem than those categorised as using self-defeating humour. This finding confirms Zeigler-Hill et al.'s (2013) findings that self-defeating targets are rated as having a lower self-esteem and further supports the notion that self-defeating and selfdeprecating humour are individual forms of humour with varying relationships with personality and wellbeing (Rawlings \& Findlay 2013).

In examining which observer variables predicted the ratings of target self-esteem, increased positive affect predicted higher ratings of self-esteem for the target using selfdeprecating humour and increased observer self-esteem predicted the ratings of self-esteem for the target using self-defeating humour. This revealed that, in line with assumed similarity research (Ready 2000), observers with higher positive affect and self-esteem were more likely to rate others as having higher self-esteem and behaving in ways consistent with positive affect. Interestingly, when examining ratings of funniness, participants found the targets using self-defeating humour slightly funnier than the comedians using self-deprecating humour do. Higher self-reported extraversion predicted funniness ratings for both humour styles, supporting previous research indicating that extraversion is a predictor of humour appreciation (Moran et al. 2014). Higher observer negative affect also significantly predicted funniness ratings for both humour styles, and it is likely that when individuals who are experiencing negative affect (i.e. negative emotions) are exposed to humorous stimuli, they are relieved from their low emotional state thus exacerbating their response to the humour.

Individual differences in personality often underlie what individuals find humorous and therefore laughter (or the lack thereof) in response to humour serves as a signal about one's unconscious preferences (Lynch 2010). As such, sharing the target's views may be significant in an individual's response to a joke. This might explain why the 'perceive' branch of emotional self-efficacy negatively predicted higher ratings of funniness for the targets using self-defeating humour, as these individuals are less confident in their ability to perceive others' emotions. In other words, these individuals were less likely to recognise the defeating undertones of this style and appreciate this humour irrespective. Observer use of aggressive humour also predicted higher funniness ratings. Aggressive humour often involves putting others down, and might explain why these individuals might have enjoyed the self-defeating target's humour (which involves putting oneself down).

\subsection{Limitations and future directions}

Whilst these findings are an exciting early step in the exploration of the perception of humour styles the conclusions drawn from these findings are limited. This study relied solely on preexisting online videos and as such the comedian's humour styles were largely unknown. This meant that we were unable to provide self-other agreement measures as we were reliant on the theoretical definitions of the humour styles to select videos reflecting each humour style. These videos also present numerous confounding variables in the delivery of humour, which might provide information about the target's humour style over and above the content of the joke. For example, audience laughter might signal that the joke was successful and could play a role in whether perceivers view the joke as self-deprecating or self-defeating. The 
participants might also have preconceived ideas about the comedian, given that they are popular, and this might have impacted on their ratings of the comedian's self-esteem and their humour styles outside of the video content. For example, if a comedian is known to be affected by mental illness this might play a role in how their self-esteem is perceived.

The results of this study indicate two clear paths for future research. A significant finding in this paper is that observers saw a measurable difference in the self-esteem of comedians using self-deprecating and self-defeating humour. Observers are likely to perceive self-esteem based on a number of target characteristics, such as physical appearance and confidence in delivering humorous material. Future research could focus more specifically on these contributing factors for the perception of self-esteem and thus the categorisation of humorous stimuli as self-defeating over self-deprecating or vice versa. This research might adopt the use of written humour stimuli, such as descriptions of targets (e.g., written vignettes) similar to that of Zeigler-Hill et al. (2013) to control for these variables.

Affect predicted the perception of the two self-disparaging humour styles, with higher positive affect predicting higher ratings of self-esteem for both the self-defeating and selfdeprecating comedians. This presents a second path for future research which might explore the effect of mood on humour style perception given that mood operates as a lens shaping one's experience and judgment of oneself and others (Forgas \& Bower 1987). For example, those in a positive mood might perceive self-disparaging content more positively (i.e. as selfdeprecating). In addition, the current study revealed that higher negative affect predicted ratings of funniness of the targets using self-defeating humour. This was explained by the function of humour in potentially providing a temporary relief from their low emotional state thus exacerbating their response to the humour. As such, measuring observer mood following the presentation of each self-disparaging humour stimulus might also provide information about how exposure to self-disparaging humour might affect mood.

The current study added to the body of literature examining humour as an interpersonal signal (Zeigler-Hill et al. 2013). The results demonstrated that the self-deprecating targets were rated as having a higher self-esteem than those using self-defeating humour, further illustrating that humour use can signal information about the target. These results confirmed the notion that self-defeating and self-deprecating humour are distinct humour styles. This has broader theoretical implications that might argue that the use of Martin et al.'s (2003) HSQ might not be sufficient in capturing all types of humour. The results of the present study also revealed that observers' personality, humour styles, and affect predicted the perception of not only the target's humour styles but also their self-esteem and funniness. This exploration confirms that the use of humour can effectively provide information about a target and offers an exciting platform for future interpersonal humour research to emerge.

\section{References}

Baumeister, R. F., Dale, K., \& Sommer, K. L. (1998). 'Freudian defence mechanisms and empirical findings in modern social psychology: Reaction formation, projection, displacement, undoing, isolation, sublimation, and denial'. Journal of Personality 66, pp. 1081-1124.

Cann, A \& Matson, C. (2014). 'Sense of humour and social desirability: Understanding how humour styles are perceived'. Personality and Individual Differences 66, pp. 176-180. doi: 10.1016/j.paid.2014.03.029

Clarke, P.J., Marshall, V. W., Ryff, C.D., \& Wheaton, B. (2001). 'Measuring psychological wellbeing in the Canadian study of health and aging'. International Psychogeriatrics 13, pp. 79-90. 
Costa, P. T., Jr., \& McCrae, R. R. (1992). The Revised NEO Personality Inventory (NEO PI-R) and NEO Five-Factor Inventory (NEO-FFI) Professional Manual. Odessa, FL: Psychological Assessment Resources.

Dacre Pool, L., \& Qualter, P. (2012). 'The dimensional structure of the Emotional SelfEfficacy Scale (ESES)'. Australian Journal of Psychology 64, pp. 147-154. doi:10.1111/j.1742-9536.2011.00039.x

Donnllan, M. B., Oswald, F. L., Baird, B. M., \& Lucas, R. E. (2006). 'The Mini-IPIP scales: Tiny-yet-effective measures of the big five factors of personality'. Psychological Assessment 18 (2), pp. 192-203.

Dozois, D. J. A., Martin, R.A., \& Bieling P. J. (2009). 'Early maladaptive schemas and adaptive/maladaptive styles of humour'. Cognitive Therapy and Research 33, pp. 585-596. doi : 10.1007/s10608-008-9223-9

Forgas, J. P., \& Bower, G. H. (1987). 'Mood effects on person-perception judgments'. Journal of Personality and Social Psychology 53, pp. 53-60.

Frewen, P. A., Brinker, J., Martin, R. A. \& Dozois, D. J. A. (2008). 'Humour styles and personality-vulnerability to depression'. Humour: International Journal of Humour Research 21, pp. 179-195. doi :10.1515/HUMOR.2008.009 0933-1719/08/0021-0179

Galloway, G. (2010). 'Individual differences in personal humour styles: Identification of prominent patterns and their associates'. Personality and Individual Differences, 48, pp. 563-567. doi.org/10.1016/j.paid.2009.12.007

Goldberg, L. R. (1992). 'The development of markers for the Big-Five factor structure'. Psychological Assessment 4, pp. 26-42.

Greven, C., Chamorro-Premuzic, T., Arteche, A., \& Furnham, A. (2008). 'A hierarchical integration of dispositional determinants of general health in students: The Big Five, trait emotional intelligence and humour styles'. Personality and Individual Differences 44, pp. 1562-1573. doi: 10.1016/j.paid.2008.01.012

Kirk, B. A., Schutte, N. S., \& Hine, D. W. (2008). 'Development and preliminary validation of an emotional self-efficacy scale'. Personality and Individual Differences 45, pp. 432-436.

Kuiper, N.A., Grimshaw, M., Leite, C., \& Kirsh, G. (2004). 'Humour is not always the best medicine: Specific components of sense of humour and psychological well-being'. Humour: International Journal of Humour Research 17, pp. 135-168.

Macgregor, J. C. D., Fitzsimons, G. M., \& Holmes, J. G. (2013) 'Perceiving low self-esteem in close others impedes capitalisation and undermines the relationship'. Personal Relationships 20, pp. 690-705.

Martin, R. A., Puhlik-Doris, P., Larsen, G., Gray, J., \& Weir, K. (2003). 'Individual differences in uses of humour and their relation to psychological well-being: Development of the Humour Styles Questionnaire'. Journal of Research in Personality 37, pp. 48-75.

Martin, R.A. (2007). The Psychology of Humour: An Integrative Approach. Burlington. MA: Elsevier Academic Press.

McCosker, B., \& Moran, C.C. (2012). 'Differential effects of self-esteem and interpersonal competence on humour styles'. Psychology Research and Behaviour Management 5, pp. 143-150.

Mendiburo-Seguel, A., Paez, D., \& Martinez-Sanchez, F. (2015) 'Humour styles and personality: A meta-analysis and the Big Five personality traits'. Personality and Social Psychology 56, pp. 335-340. doi: 10.1111/sjop.12209

Moran, J. M., Rain, M., Page-Gould, Mar, R.A. (2014) 'Do I amuse you? Asymmetric predictors for humour appreciation and humour production'. Journal of Research in Personality 49, pp. 8-13. http://dx.doi.org/10.1016/j.jrp.2013.12.002 
Rawlings, M. R \& Findlay, B. M. (2013). 'A scale for self-deprecating humour.' Paper presented at the $10^{\text {th }}$ Colloquium of the Australian Humour Studies Network, Newcastle, Australia.

Ready, R. E., Clark, L. A., Watson, D., \& Westerhouse, K. (2000). 'Self-and peer-reported personality: Agreement, trait rateability, and the "self-based heuristic".' Journal of Research in Personality 34, pp. 208-224.

Rosenberg, M. (1965). Society and the Adolescent Self-Image. Princeton, NJ: Princeton University Press.

Ruch, W. (1998). The Sense of Humour: Explorations of a Personality Characteristic. New York: Mouton De Gruyter.

Ryff, C., \& Keyes, C. (1995). 'The structure of psychological well-being revisited'. Journal of Personality and Social Psychology 69, pp. 719-727.

Saroglou, V., \& Scariot, C. (2002). 'Humour styles questionnaire: Personality and educational correlates in Belgian high school and college students'. European Journal of Personality 16, pp. 43-54.

Schermer, J. A., Martin, R. A., Martin, N. G., Lynskey, M. \& Vern, P. A. (2013). 'The general factor of personality and humour styles'. Personality and Individual Differences 5, pp. 890-893.

Tabachnick, B. G. \& Fidell, L. S. (2012). Using Multivariate Statistics (6th edition). New York, NY: Allyn \& Bacon

Vernon, P. A., Martin, R. A., Schermer, J. A., \& Mackie, A. (2008). 'A behavioural genetic investigation of humour styles and their correlations with the Big-5 personality dimensions'. Personality and Individual Differences 44, pp. 1116-1125.

Veselka, L., Schermer, J. A., Martin, R. A., Cherkas, L. F., Spector, T., \& Vernon, P. A. (2010). 'A behavioural genetic study of relationships between humour styles and the six HEXACO personality factors'. Europe's Journal of Psychology 6, pp. 9-33.

Watson, D., Clark. L. A., \& Tellegen, A. (1988). 'Brief measures of Positive and Negative Affect: The PANAS Scale'. Social Psychology 54, pp. 1063-1070.

Watson, D., Hubbard, B., \& Wiese, D. (2000). 'Self-other agreement in personality and affectivity: The role of acquaintanceship, trait visibility, and assumed similarity'. Journal of Personality and Social Psychology 78, pp. 1063-1070.

Zeigler-Hill, V., Besser, A., \& Jett, S. E. (2013). 'Laughing at the looking glass: Does humour style serve as an interpersonal signal?’ Evolutionary Psychology 11, pp. 201-226. 